\title{
O metaparadigma cultural, a Teoria da Literatura \\ e a Literatura Comparada - um lugar para a lusofonia
}

\author{
Maria da Penha Campos Fernandes ${ }^{1}$
}

Este trabalho focaliza o problema da mutação dos fundamentos do campo dos Estudos Literários, frequentemente sistematizados pela tradição europeia com o sentido de essencializar e universalizar a alta Cultura e a Civilização ditas Ocidentais, embora ambas tenham sido padronizadas e canonizadas de modo específico por elites intelectuais, ideológicas, políticas e nacionais nomeadamente masculinas - uma hegemonia que vem sendo abalada mais profundamente a partir da II Guerra Mundial, face à emergência local e transcontinental de vozes antes silenciadas.

O seu enfoque privilegia a construção da identidade de duas disciplinas, a Teoria da Literatura e a Literatura Comparada, enquanto peças de um jogo curricular em processo com as actuais forças da transversalidade de uma "Teoria" sem designativo que a especifique e dos Estudos Culturais, atentos às discriminações, intercâmbios e diferenças dos tipos e dos níveis de cultura. Uma questão que afeta as fronteiras curriculares mais estabelecidas e que se revela, pela sua extensão e

1 Uma versão do presente ensaio, intitulada "O trânsito da Teoria da Literatura e da Literatura Comparada: um lugar para a Lusofonia", foi apresentada no XXII Congresso Internacional de Professores de Literatura Portuguesa (Salvador, Bahia, 2009). A autora tem o Doutoramento em Teoria da Literatura e é Professora Associada de nomeação definitiva ("tenure»), na Universidade do Minho (Braga, Portugal). 
profundidade, como uma mudança de metaparadigma cultural global, no qual a necessária remodelização dos Estudos Literários carece da ativação do diálogo com o contributo plurissistêmico da Lusofonia - dos Estudos Lusófonos, das Culturas e das Literaturas Lusófonas -, até há bem pouco tempo marginalizado.

1. ESTUDOS LITERÁRIOS E MUDANÇAS DE PARADIGMA: HISTORICISMO, TEXTUALISMO, CULTURALISMO

A palavra "literatura", reiterada no título para designar duas disciplinas das chamadas Humanidades, tem-se mostrado incómoda sempre que se pretenda referir com ela um objeto de conhecimento estável e universal. Embora esta constatação não seja nova, pois nas Histórias das Literaturas Nacionais abundam referências a obras heterogêneas sob diferentes aspectos, é certo que existe algum consenso dos especialistas em torno da actual "crise" dos Estudos Literários: uma ideia agravada pela consciencialização da insuficiência das noções "literariedade" e de "função poétican, as quais, tal como foram delineadas pelos formalistas e estruturalistas em termos descritivos de dominância do significante textual, fizeram recrudescer o desejo de objetividade e cientificidade: se a Linguística fora constituída em ciência da língua, também os estudos de Teoria da Literatura/ Poética Literária poderiam ter esta pretensão, uma esperança que nos permite situar nas décadas de 60 e 70 o acme do paradigma textualista ${ }^{1}$.

Os Estudos Literários, enquanto espaço pluridisciplinar de organização do conhecimento da Literatura $^{2}$, mantêm uma relação amorosa não resolvida com a cientificidade. Uma irresolução que afeta diretamente a Teoria da Literatura, concebida que foi com o compromisso de sistematizar os fundamentos do seu objeto de conhecimento, o que a torna uma espécie de hiperdisciplina de teor analítico e sintético globalizante, à qual não escapa a Literatura Comparada, conforme no-lo demonstra o seu principal marco, a Theory of Literature de René Wellek e Austin Warren, 1949. Nesta obra então inovadora, a crítica das 
sobrevivências do cientismo oitocentista incide sobre a restrição de um conceito de verdade científica que excluía as realizações das Humanidades. Uma denúncia que, no entanto, não implicava a alienação do mesmo, visto que a abrangência das informações que estes investigadores apresentavam era, e é, inquestionável: seja por distinguirem os Estudos Literários intrínsecos dos extrínsecos (estes relacionados com a biografia, a psicologia, a sociologia, as "ideias" e as "outras artes»); seja por incluírem, sob a designação de "teoria da literatura", a "teoria do criticismo literário" e a "teoria da história literária", ambas "tão necessárias»; seja pelo posicionamento assumido no famoso capítulo, "Literatura Geral, Literatura Comparada e Literatura Nacional», onde a distinção estabelecida por Paul Van Tieghem entre as duas primeiras disciplinas é considerada insustentável ${ }^{3}$. Do ponto de vista da sistematização de uma Teoria da Literatura internacional e da Literatura Geral por Wellek e Warren, a amplificação do objecto da Literatura Comparada não podia deixar de implicar o reconhecimento da funcionalidade dos estudos comparados para o conhecimento de um objeto mais amplo - a literatura -, uma evidência metodológica que justificava a importância desta disciplina na reflexão posterior do primeiro investigador.

O sucesso internacional deste manual de Theory of Literature foi notório. E foi medido pelo próprio Wellek, no "Prefácio à terceira edição americana", que assina sozinho, pelas traduções do livro em oito idiomas, "espanhol, italiano, japonês, coreano, alemão, português, hebraico e gujarati, nessa ordem». Um registo que tanto confirma o destino cosmopolita da obra como o avanço da sistematização teórico-literária para fora das fronteiras europeias ${ }^{4}$, mesmo que estas continuassem a ser o fulcro das atenções do investigador, que, pela mesma época, republica um ensaio sobre o estado da investigação no seu continente de origem, "A revolta contra o positivismo na erudição europeia recente» 5 : neste ensaio, reconhece como traços distintivos dos "estudos literários tradicionais" de então, por um lado, o cientismo do século XIX, que chegou a defender a transposição dos métodos das "ciências naturais" para o estudo da literatura, privilegiando a origem e a causalidade; por outro, a erudição 
passadista, dedicada ao historicismo, à recolha de fontes e pormenores factuais insignificantes. Duas sobrevivências de um "positivismo" equívoco e de um ideal de "ciência" impróprio às Humanidades:

Assim, os estudiosos de literatura tornaram-se cientistas ou antes pseudocientistas. Como chegaram tarde ao campo e manejavam um material intratável, foram geralmente maus cientistas ou de segunda ordem, que se sentiam no dever de defender seu tema e só vagamente tinham confiança em seus métodos de abordagem. Esta é de certo uma caracterização supersimplificada da cultura literária por volta de 1900; mas ouso dizer que todos reconhecemos hoje as suas sobrevivências na América e em outras partes ${ }^{6}$.

Ainda em Concepts of Criticism, inclui-se o ensaio "A crise da Literatura Comparada", que retoma a polémica conferência do autor em $1958^{7}$, situando a precariedade desta disciplina no âmbito da crise da "erudição literária", então vista como ameaçada pela "mão mortal do factualismo, do cientismo e do relativismo histórico do século XIX" ${ }^{8}$. A necessidade da alteração desta matriz disciplinar é recorrente na reflexão de Wellek, o qual, na qualidade de Presidente da American Comparative Literature Association (A.C.L.A.), profere o discurso, "A Literatura Comparada hoje" (1965), depois integrado no seu livro, Discriminations. Further Concepts of Criticism (1970).

Por esta época, os vasos comunicantes intercontinentais permitiram que Jacques Derrida proferisse, nos Estados Unidos, em 1966, a conferência "Structure, Sign and Play in the Discourse of Human Science" ${ }^{9}$, de cujo impacto ainda hoje colhemos as consequências práticas e teóricas. Os Estudos Literários alteravam-se substancialmente, sendo de lembrar, no contexto francês, a polémica obra Critique et verité (1966), na qual Roland Barthes trazia à baila a ausência da verdade positiva na crítica afeita ao positivismo, que era caracterizada apenas pelo verosimil crítico e não pela "verdade»: "Aristóteles estabeleceu a técnica da fala fingida a partir da existência de um certo verosímil, depositado no espírito dos homens pela tradição, pelos Sábios, pela maioria, pela opinião pública, etc. O verosímil é aquilo que, numa obra ou num discurso, não 
contradiz qualquer destas autoridades. [...] Numa palavra, existe o verosímil crítico. [...] Quais são então as regras do verosímil crítico em 1965?»10. A resposta a esta questão arrolava as seguintes regras: a objetividade, confundida com a crença no sentido legítimo da obra literária; o gosto, consubstanciado num conjunto das interdições morais e estéticas; a clareza ou a exigência de "um idioma sagrado", estabelecendo "uma relação fácil com uma média de todos os leitores possíveis"; a assimbolia ou a incapacidade para "perceber ou manejar símbolos, isto é, coexistências de sentidos» 11 .

A preocupação da A.C.L.A. com os "modelos" disciplinares da Literatura Comparada perpassa os seus relatórios de 1965, 1975 e 199312, de modo que o terceiro Report on Professional Standards, conhecido como "Bernheimer Report, 1993. Comparative Literature at the Turn of Century" ${ }^{13}$, descreve a forte alteração da matriz disciplinar da Literatura Comparada sob a influência dos Estudos Culturais /Étnicos/de Género/Semióticos. Adotando um procedimento comparativo face aos relatórios anteriores, este relatório reconhece-lhes o mérito de definirem "no essencial a concepção" dominante da disciplina nos Estados Unidos, após a II Guerra mundial, especialmente nos anos 50-70, quando se impusera a necessidade de defender a hegemonia e a unidade da cultura europeia - uma questão de ordem ideológica, política e económica, mas com reflexos nos conteúdos e objetivos da Literatura Comparada, a qual, acentuando a sua abertura internacional, buscava identificar motivos $e$ temas; ampliar o conhecimento dos modos e géneros do discurso; valorizar o estudo das linguas para reforçar as identidades nacionais; produzir uma elite intelectual capaz de ler as obras canonizadas nas linguas originais, ainda que o texto de 1965 admitisse o uso minoritário de traduções de obras em linguas pouco conhecidas. Neste tempo do pós-guerra e da chamada Guerra Fria, o eurocentrismo elitista e erudito era o traço dominante da disciplina:

Em qualquer circunstância, a perspectiva alargada raramente foi além da Europa e da tradição europeia da cultura erudita que remonta às civilizações da 
antiguidade clássica. (...) A Europa é a sede dos originais canónicos, o objecto próprio do estudo comparatista; as chamadas culturas remotas são periféricas à disciplina e por isso podem ser estudadas em traduções ${ }^{14}$.

Segundo o relatório de 1975, este eurocentrismo erudito da Literatura Comparada, que era assegurado pela seleção dos melhores alunos nas universidades mais preparadas, contraponteia com o receio de degradação da disciplina, seja pela multiplicação dos programas interdisciplinares, que ameaçavam as suas fronteiras, a sua unidade e coesão; seja pelo sucesso académico da Teoria da Literatura que, sob a égide estruturalista da sincronia, investira contra a erudição historicista da Literatura Comparada. Estes receios foram efetivamente confirmados. Assim, o "Relatório Bernheimer" constata que as práticas adotadas no "espaço da comparação" já não correspondiam às diretrizes disciplinares anteriormente expostas e resume com excelência as suas novas linhas de força:

O espaço da comparação envolve hoje comparações entre produções artísticas geralmente estudadas por disciplinas diferentes; entre várias construções culturais dessas disciplinas; entre tradições culturais do Ocidente, tanto populares como eruditas, e as culturas não ocidentais; entre produções culturais de povos colonizados, dos tempos de pré- e do pós- contato; entre construções de sexualidade definidas como femininas e como masculinas, ou entre orientações sexuais definidas como hetero ou homo; entre modos raciais e étnicos de significação; entre definições hermenêuticas de sentido e análises materialistas dos seus modos de produção e circulação; e muito mais. Estas maneiras de contextualizar a literatura nos campos alargados do discurso, da cultura, da ideologia, da raça e da sexualidade, são tão diferentes dos antigos modelos do estudo literário segundo autores, nações, períodos e géneros, que o termo "literatura" pode já não descrever adequadamente o nosso objeto de estudos. ${ }^{15}$

Encontram-se nesta sintese as linhas de força que reconhecemos hoje serem as dos atuais Estudos Culturais e outros, ante cuja proliferação se situa a Literatura Comparada - uma disciplina que, a manter esta designação, não pode perder de vista o objetivo de conhecer o espaço da Literatura, em suas dimensões artística e metacrítica, 
colaborando assim, de modo produtivo com uma Teoria da Literatura que não se estagne, que saiba redimensionar criticamente a sua tradição e que não se amedronte ante a rede de conexões multi- e interculturais, ante a plurilegilibilidade do seu objeto de conhecimento, inevitavelmente dinâmico, já que modelizado por forças enunciativas em interação.

\section{O METAPARADIGMA CULTURAL E OS ESTUDOS LITERÁRIOS}

\subsection{O impacto da "Teoria"}

"O Relatório Bernheimer, 1993" certifica uma viragem dos Estudos Literários, assinalada pelo reconhecimento universitário dos Estudos Culturais e conexos, ocorrida por volta dos anos 80. Um momento em que Terry Eagleton publica o seu interessante e irónico manual, Literary Theory (1983), no qual começa por indagar o que é a Literatura, para problematizar as definições mais estabelecidas:

a literatura não é sempre "escrita imaginativa", pois a antinomia corrente "factos"/ "ficção" não é estável, chegando a ser mesmo frequentemente questionável;

a literatura não é uma "organização particular da linguagem" porque não existe uma linguagem "normal» comum a toda gente, além disso, nem a "estranheza", nem a "auto-referencialidade", nem a "nãopragmaticidade" a garantem;

a literatura não é um "valor" estável e objectivo, depende de como a leem, o que não lhe permite ter uma "essência" - o que é literatura depende profundamente das estruturas de crença e dos juizos de valor comprometidos com as ideologias sociais variáveis historicamente ${ }^{16}$.

O manual termina de modo agónico, pois o estudo dogmático paralisara, diz Eagleton, a historicidade da literatura, sendo o formalismo crítico e o costumeiro manancial de verdades eternas usados preconceituosamente. No entanto, o "leão", uma referência metafórica aos bons textos dos bons autores, "é mais forte que o domador" e foi apenas adormecido. É preciso acordá-10 ${ }^{17}$. Provavelmente por isso, este livro de Literary Theory é também um lauto desfile de informações teóricas de 
diversa proveniência disciplinar ("Theory"), nas quais são sintetizadas as principais correntes novecentistas de pensamento ${ }^{18}$.

Em sintese: a Literatura, tal como fora estudada, morrera. É preciso ressuscitá-la com a nossa nova inquietação teórica, que é o mesmo que a espicaçar com uma diversidade de modos de ver e de ler.

A ressurreição, porém, não tem sido pacífica. Não se poupam ataques acadêmicos à Teoria da Literatura, uma discussão que ultrapassa os parâmetros da disputa normal entre teorias, chegando mesmo a teorizar-se, paradoxalmente, contra a "Teoria»19; também se tecem profecias sobre a morte da Literatura Comparada, cujas fronteiras foram invadidas por elementos que se apresentavam como estranhos, como ocorre com os chamados Estudos de Área ${ }^{20}$, em cujo domínio pode colocar-se o projeto dos Estudos Interculturais, comprometido com a aproximação literária entre o Ocidente e o Oriente ${ }^{21}$.

$\mathrm{E}$ é neste interim que se erige com vigor uma noção de "Teoria" sem objeto específico, um "gênero miscelânea" de discursos com raízes no século XIX, representado por um conjunto de vozes de vários campos do conhecimento a partir dos quais são desafiados os modos comuns de pensar de outros campos 22 .

No seu tão sintético quanto desafiador manual, Literary Theory, A Very Short Introduction (1997), Jonathan Culler aborda as relações entre "Teoria" e Teoria da Literatura, afirmando a desarticulação dos fundamentos desta por aquela, que é representada por uma colecção de nomes conhecidos ${ }^{23}$, cujos trabalhos foram sendo introduzidos, desde os anos 60, no âmbito dos Estudos Literários, por renovarem a reflexão sobre importantes questões e terem efeitos práticos. Discorrendo sobre os efeitos da "Teoria", Culler comenta a reflexão de Foucault sobre a noção de sexo como efeito histórico da cultura, como construção desta ${ }^{24}$; comenta ainda as noções de escrita e suplemento em Derrida, que redundam na crítica à ideia de que existe uma realidade fora do texto, ou seja, fora do movimento dos signos $^{25}$. Dois autores que põem em causa as noções ingénuas de natureza e realidade. 
Em verdade, duas noções ingênuas sobre as quais se tem pautado (dizemos nós) a pseudocompreensão do funcionamento da mimese poéticoliterária ${ }^{26}$ enquanto fenômeno de comunicação, uma pseudocompreensão sobre a qual se tem erigido boa parte do pensamento teórico-literário no século XX.

Constituindo-se em pensamento sobre pensamento, a "Teoria" reage:

contra a ideia de que o significado de um enunciado ou discurso se reduz ao que o autor "tinha em mente»;

reage contra a ideia de que a verdade de uma expressão reside fora do texto, na experiência ou situação de que fala;

reage contra a noção de que a realidade é o que está 'presente' num dado momento.

Em suma:

The genre of 'theory' includes works of anthropology, art history, film studies, gender studies, linguistics, philosophy, political theory, psychoanalysis, science studies, social and intellectual history and sociology (...) Works that become 'theory' offer accounts others can use about meaning, nature and culture, the functioning of the psyche, the relations of public to private experience and of larger historical forces to individual experience. (...) The main effect of theory is the disputing of 'common sense': common-sense views about meaning, writing, literature, experience. (...) As a critique of the common sense and exploration of alternative conceptions, theory involves a questioning of the most basic premises or assumptions of literary study, the unsettling of anything that might have been taken for granted: What meaning? What is an author? What is to read? What is the "I" or subject who writes, reads or acts? How the texts relate to the circumstances' in which they are produced? 27

Esta sequência de indagações traça um roteiro de diferenças através do qual é possivel inferir-se o impacto da teoria pós-estruturalista, juntamente com a desconstrução, sobre o campo dos Estudos Literários, onde os membros mais arraigados aos paradigmas tradicionais, sobretudo quando mais comprometidos com o movimento editorial e comercial 
relativo à venda das suas obras, tendem a bloquear o fluxo das novas investigações necessárias ao desenvolvimento do campo, já que estas lhes impõem a obrigação de reverem criticamente e em profundidade, numa vigilância contínua, a pertinência do léxico metalinguístico a que foram habituados, que ensinaram e continuam a divulgar ${ }^{28}$. Neste ponto, a institucionalização dos Estudos Literários ostentando-se contra si mesma, metamorfoseia o desejo de ciência em desejo de ribalta para esta ou aquela figura académica. E esta "guerra de linguagens", perspectivas e matrizes disciplinares também é parte dos Estudos Literários e do que se compreende como Literatura.

2.2.Um novo regime de racionalidade: o lugar do sujeito teórico na era da "glocalização"

"What is an author?» 29 No actual metaparadigma cultural, com efeitos sobre diferentes matrizes disciplinares, a problematização das relações do autor com a linguagem que usa é, sem dúvida, uma das mais interessantes contribuições da "Teoria". Dando continuidade a este projeto, chega-se à necessidade de refletir sobre o relacionamento do sujeito teórico, mais exactamente do sujeito da escrita teórica, com o seu próprio discurso, pois o enquadramento da diade subjetividade / objetividade alterou-se:

The point I'm trying to make is that scholars studying the culture to which they belong (national, ethnic, or gender cultures) are not necessarily subjective, just scholars studying cultures to which they do not belong are not necessarily objective. Since I believe that theories are not instruments to understand something that lies outside the theory but, on the contrary, that theories are instruments to construct knowledge and understanding (...) For, if we approach knowledge and understanding from the point of view of a constructivist epistemology and hermeneutics, the audience being addressed and research's agenda are as relevant to the construction of the object or subject being studies as are the subject or object being constructed. Thus the locus of enunciation is as much a part of knowledge and understanding as it is the construction of the image of 
"real" resulting from a disciplinary discourse (...) Consequently, the "true" (...) will be transact in the respective communities of interpretation as much for its correspondence to what is taken for "real" as for the authorizing locus of enunciation constructed in the very act of describing an object or a subject. ${ }^{30}$

A importância da problematização do conceito de autor ganha relevo quando se observa, por exemplo, que as Histórias da Literatura enraizadas no paradigma positivista centraram a sua estrutura numa noção de autor (empírico) assumida como axiomática e, como tal, não merecedora de discussão. Um paradigma de que derivava, por certo, a exigência de distanciamento do sujeito da escrita teórica em relação à mesma, levandoo a ocultar-se linguisticamente, de modo a forjar a ilusão de objetividade da informação classificada como científica. A tentativa de expungir o sujeito teórico fora também reforçada pela hipótese da verdade da metalinguagem - especialmente requerida no âmbito das ciências "exatas" pelo positivismo lógico desenvolvido pelo Círculo de Viena entre as duas grandes guerras -, mas não deixou de afetar outros setores do conhecimento.

Daí, no campo das Humanidades, a atual crítica à intenção de travestir a investigação numa tela de palavras supostamente assexuadas e não situadas em termos sociais, étnicos e geográficos, na qual se registrava um acúmulo de "fatos" e outros "dados" pretensamente imunes à interpretação de alguém: uma estratégia retórica que parecia funcionar como garantia de objetividade, neutralidade e certeza, sintetizadas na etiqueta do "rigor científico", uma etiqueta tantas vezes utilizada para mascarar parcialidades e interesses políticos em posicionamentos teóricocríticos, agora em processo de desmascaração.

O dominio da Teoria da Literatura não foi imune a esta retórica ${ }^{31}$. Indagar até que ponto o manual de Wellek - Warren, embora esparsamente pontuado por índices linguísticos dos sujeitos, escapa à tradição positivista, de cujo historicismo pretende afastar-se, ou fica preso ao fenómeno da "cegueira da crítica»32, é uma questão que ficará no ar. De qualquer forma, o desejo de ciência da Teoria da Literatura impôs-se sob a 
exigência do recalque da sua condição de discurso enunciado por um sujeito - uma convenção que não significa, como é óbvio, que os manuais da disciplina carecem de autores ou de edições localizadas e datadas, mas sim que o corpo do discurso teórico e da respectiva prática deveria ser vazado num estilo informativo, objetivo, descritivo e neutral ${ }^{33}$. Aliás, uma estratégia acentuada pela indole universalizante dos manuais desta disciplina - intitulados simplesmente Teoria da Literatura —, já que neles o termo "Literatura" brilha sem modificador que o especifique, nem mesmo o hiperbólico adjetivo "Ocidental».

Os modos de produção do conhecimento científico não se libertam das respectivas circunstâncias e dos sujeitos. Um fato que vai além das informações superficiais contidas, por exemplo, na capa de um livro, na ficha técnica deste, ou mesmo num mero índice linguístico relativo ao autor.

Esta é, sem dúvida, a mais importante lição provocada pelo rescaldo do funcionamento de correntes de pensamento - como o Marxismo, o Existencialismo, o Estruturalismo, o Pós-estruturalismo e a Desconstrução -, que, depois da II Guerra Mundial, se foram consolidando e expandindo, através de hibridismos sui generis e transformações por vezes sutis, seja em diálogo crítico no interior do próprio espaço, seja em confronto com posicionamentos diversos. Ante a opressão, a náusea, a iminência da morte do sujeito na linguagem, as várias formas de discriminação empírica, o que se impõe é a necessidade da resistência deste sujeito nos interstícios das linguagens como forma de remodelização dos universos culturais. Uma atitude intensamente agenciada pelo Pós-colonialismo e pela Teoria Crítica Feminista, duas poderosas ventanias sobre a "velha questão" do cânone»34 literário - uma questão por vezes confundida com santificação dos mesmos verdadeiros santos, numa igreja em que todos os altares já foram ocupados.

$\mathrm{Na}$ heterogeneidade dos polissistemas ${ }^{35}$ culturais, observa-se que as mudanças não se fazem nunca em completa simultaneidade e nem mesmo com perfeição. Em 1949, o mesmo ano da primeira edição do manual de René Wellek e Austin Warren, Simone Beauvoir, no contexto da "querela 
feminina", publica Le deuxième sexe, uma obra cuja importância não foi prontamente reconhecida no campo de Teoria da Literatura. Posicionandose contra a teoria da natureza essencial ou estática, consubstanciada na noção do "eterno feminino", a autora estabelece laços relacionais de teor comparativo com outras existências subalternizadas, de modo a delinear com maior nitidez o objeto sob análise: "as mulheres não são como os negros da América, como os judeus, uma minoria». E, mais adiante, depois de comentar a problemática da subordinação feminina, lembra que "a diáspora judia, a introdução da escravatura na América, as conquistas coloniais são fatos datados", acrescentando que, nestes casos, bem como no do proletariado, a inscrição temporal é mais evidente: "houve um antes: eles [os oprimidos] têm em comum um passado, uma tradição, por vezes uma religião, uma cultura", ao passo que o problema da mulher parece escapar à história, daí parecer que é um absoluto ${ }^{36}$.

Uma teorização que obriga a rever o que seja a "natureza feminina". E que é tangente com a questão da "imitação da natureza", a qual percorre a tradição literária através dos séculos, mas que não foi aproveitada pela enunciação masculina dos manuais de Teoria da Literatura mais conhecidos para repensar criticamente e em profundidade a história teórica do seu campo de trabalho. As reflexões de Simone Beauvoir incidem sobre diferenças culturais que foram invisibilizadas com maior frequência que o admissivel, mas que se situam bem no centro das noções universalizantes de "Homem" e de "Natureza", problematizando-as. Falar da mulher é, com certeza, refletir sobre a questão basilar do corpo, usualmente reduzida à categoria do "natural", mas é, sobretudo, observar os efeitos pragmáticos dos discursos que, sobre este assunto, as tradições culturais formataram e naturalizaram - a tradição dos Estudos Literários inclusive.

O reconhecimento do valor teórico do sujeito ultrapassa as fronteiras da questão do sujeito feminino, faz-se reconhecimento da importância do sujeito teórico, enquanto coletor e produtor de conhecimentos situados entre coordenadas de várias ordens ${ }^{37}$. Uma questão epistemológica que tem sido ressaltada por outras correntes do pensamento e que coloca sob 
suspeita ou sob análise os conceitos absolutos de Ciência e de Verdade neutrais. Isto nos leva à valorização teórica do sujeito empírico culturalizado. Se o sujeito é sufocado pela espessura das linguagens, é preciso esgarçá-las, de modo a permitir que ele próprio respire e se torne visivel.

Qualquer uma destas correntes teóricas, a Teoria e a crítica feminina e o Pós-colonialismo38, cujas práticas são pautadas pela visibilidade das coordenadas da enunciação, ilustra bem a tendência para desmistificação de estereótipos humanistas, designada por Jean-Paul Sartre como o "striptease de notre humanisme». Ambas permitem que se ressalte, sob a capa do universalismo abstrato e idealista do humanismo clássico, a veemência da carne, também ela humana, o que não se cinge à mera observação da presença eventual de índices linguísticos do sujeito no discurso. Estas correntes proporcionam uma revisão profunda do enquadramento das subjetividades teóricas, orientando-nos para a observação do relacionamento destas com os paradigmas dominantes nos polissistemas culturais, mas também para a análise do compromisso destes paradigmas com comunidades específicas, de modo que possam ser conhecidas as linhas enunciativas da sua localização, nem sempre convergentes: se, com Simone Beauvoir, a leitura da subalternidade do feminino emerge em situação existencial num centro cosmopolita da cultura europeia, com Fanon, um dos mais importantes teóricos da pós-colonialidade, a subalternidade étnica do negro justapõe-se à do colonizado e à do homem culto territorialmente deslocado e em situação de alerta.

Chegamos, então àquele ponto em que o sujeito da enunciação se perde na linguagem que o constitui ${ }^{39}$, mas também se revela numa encruzilhada singular de tempos e de experiências de vida, manifesta através hibridismos linguísticos e culturais.

A atual legitimação da funcionalidade enunciativa do sujeito teórico $e$ metateórico é, portanto, muito mais que uma simples aceitação dos índices linguísticos eventuais da presença deste no discurso do conhecimento. Significa que as relações entre os sujeitos e os sistemas são interativas e complexas e que as subjetividades, sobretudo porque construidas 
culturalmente no interior de linguagens submetidas a cruzamentos assimétricos e contradições por resolver, não deixam de usufruir de um potencial específico de ação.

No presente contexto epistemológico, a reflexão do sujeito teórico mostra-se mais uma atuação ou uma tomada de decisão diante da prática existencial que uma simples abstração. Isto tem, dentre outras, implicações ao nível da escrita da teoria, como é confirmado por obras paradigmáticas como as de Roland Barthes e Terry Eagleton, nas quais não se denega a densidade de um estilo muito próprio de exposição, onde recursos retóricos como a metáfora ou a ironia - porque mostram os seus préstimos na construção do conhecimento -, não se intimidam face à acusação de serem manifestações impuras, "maculadas pela ideologia" ou "pseudopoéticas".

Encontramo-nos no cerne de um outro regime de racionalidade que Boaventura Sousa Santos descreve como uma mudança de paradigma, reconhecendo a atenção deste paradigma às necessidades do chamado "senso comum" 40 : a autoconsciência crítica das debilidades e das assimetrias, a humildade científica, a abertura às vicissitudes das linguagens integram-no. $\mathrm{E}$ isto exige não somente a mudança desta e daquela matriz disciplinar até então partilhada consensualmente pela respectiva comunidade de especialista ${ }^{41}$, mas também uma profunda transformação do sujeito teórico. Trata-se de um outro regime do fazer teórico, mas que não elimina os resquícios do "positivismo", com os quais chega a interagir de modo produtivo; trata-se ainda de um outro universalismo, que alguns autores, para evitarem o problema dos universais, preferem designar como glocalização (globalização + localização) ${ }^{42}$.

Neste ponto, uma pausa para observarmos que as questões póscoloniais, multiculturais, étnicas e de géneros sexuais, comprometidas com as conquistas desconstrutoras da "Teoria", deram lugar a formulações que extrapolam diferentes fronteiras disciplinares e campos do saber, motivo por que parece mais adequado tratar a alteração do regime de racionalidade subjacente a tais formulações não como mudança restrita de 
matriz disciplinar (envolve uma teoria ou conjunto de teorias) ou mesmo de paradigma científico (envolve pressuposições subjacentes às teorias), mas antes como uma alteração epistemológica de metaparadigma cultural: pela sua profundidade e extensão, esta mudança atinge as raízes das chamadas Ciências Humanas e das Ciências Sociais, embora não só, ao comprometer as razões que apartaram estes dois ramos e conduziram à institucionalização tradicional do campo pluridisciplinar dos Estudos Literários.

Observemos, ainda, que as matrizes disciplinares tradicionais da Teoria da Literatura e da Literatura Comparada foram construídas no eixo de três falácias epistemológicas, que o atual metaparadigma cultural procura superar:

a) o ocultamento máximo do sujeito teórico e respectivas coordenadas enunciativas em nome de uma suposta "objetividade»;

b) a elisão da origem geocultural dos argumentos hegemónicos, os quais, frequentemente elevados a "ocidentais", acabaram por ser autoprojetados para o resto do mundo como "universais";

c) a não-relevância da heterogeneidade intrínseca às culturas enquanto polissistemas ${ }^{43}$, o que alicerçava um entendimento predominantemente monológico das questões literárias nacionais e não plurilógico.

Uma tríade de argumentos que cumpre reequacionar no processo da construção do conhecimento glocalizado, no cerne da tensão e da interação entre o global e o local, entre o homogéneo e o heterogéneo, de modo a receber os legados de uma pluralidade de tradições culturais. Uma tarefa que tem implicações hermenêuticas e epistemológicas, visto que, ao requerer o reconhecimento do locus enunciativo como parte integrante dos processos de compreensão, de conhecimento e de construção das imagens das realidades resultantes de diferentes abordagens, obriga à reconsideração e análise dos termos objetividade e subjetividade em função das regras culturais motivadas e partilhadas geo-historicasocialmente, que prevalecem ou não sobre os desejos e interesses pessoais, o que afecta tanto o enquadramento da correspondência entre "verdade" e 
"realidade" como a dos argumentos de autoridade:

Furthermore, the locus of enunciation of the discourse being interpreted would not be understood in itself but in the context of previous loci or enunciation that the current discourse contests, corrects, and/or expands. It is as much the saying (and the audience involved) as it is what is said (and the world referred to) that preserves or transforms the image of the real constructed by previous acts of saying and previous utterances. ${ }^{44}$

Ao enfatizar a construção dinâmica do conhecimento, este metaparadigma cultural, que ressalta o funcionamento pragmático das teorias e instituições e tem múltiplas implicações académicas sobre a gestão científica e pedagógica de diferentes curricula e matrizes disciplinares, ora vai pondo em causa a existência de cursos e disciplinas, ora vai obrigando à mudança ou à revisão de programas escolares, sempre que haja docentes que, abdicando ou não da importante tradição humanística, optem pela autenticidade de um diálogo crítico com as diferenças ${ }^{45}$. Uma mudança que extrapola em muito a interacção da Teoria da Literatura com a da Literatura Comparada, já que as respectivas identidades se transformam, revelando-as manifestamente como duas áreas disciplinares do campo dos Estudos Semióticos e Culturais, onde a organização dos cânones literários faz necessariamente parte de um jogo com os demais cânones socioculturais e as respectivas margens.

\section{UM LUGAR PARA A LUSOFONIA: LUSO-AFONIAS, LUSOFONIAS}

— Isto que está a cantar é um pássaro?

- É, sim.

- E como se chama o pássaro? - quis eu saber.

- Bom este pássaro, nós aqui em Niassa não chamamos bem pássaro. Chamamos de sapo.

(Mia Couto, 2001, in 2009:183-198)46

Ao abordar de modo tangente a questão da lusofonia, a partir de um ponto de vista que não é diretamente linguístico, tomo de empréstimo na epígrafe um diálogo presente numa das micronarrativas de Mia Couto, tão 
úteis neste tempo em que parece prevalecer, pelo menos em alguns setores dos grandes centros urbanos, a pós-moderna crise das "metanarrativas", i.e., as "grandes narrativas" religiosas, científicas, económicas, políticas, etc., que asseguram as esperanças na Salvação, na Verdade, no Progresso, na Igualdade de classes, etc ${ }^{47}$. É esta a primeira das micro-histórias integradas no ensaio "Luso-afonias - a Lusofonia entre viagens e crimes" do referido escritor moçambicano e mostra-se estruturada sob a forma de um diálogo entre o escritor e um dos habitantes de Niassa, uma terra onde uma retórica de raiz oriental ensina que "Não negar é uma educação". Para lá da diferença entre sapos e pássaros, que é consensual para qualquer falante do português, salta à vista a diferença entre modos de dizer, de pensar, de agir, enfim de ser, entre dois interlocutores pertencentes a duas regiões de um mesmo país, no caso Moçambique, mas poderia ser qualquer outro, inclusive Portugal.

Efetivamente, quando utilizamos a nossa lingua supostamente comum, acionamos diferenças de variável espessura e engolimos, com certeza, sempre alguns sapos que são chamados de pássaros ou viceversa. Percebemos então que os modos de produção dos sentidos poéticos têm as suas versões rotineiras na experiência das nossas vidas, sempre que as palavras se deslocam dos seus lugares semânticos habituais, ao nível da chamada "linguagem ordinária", para conquistarem espaços anteriormente não adivinhados, ensinando-nos uma dança produtiva de interpretações e sugestões que nos obriga a novos passos, como ocorre também nos casos de gíria.

O dominio da lusofonia é um lugar de lugares, onde têm assento os silêncios, a debilitação, a perda ou a força de vozes. Envolve convergências, memórias, trânsitos, divergências, tangências, partilhas, intersecções, versões. É um lugar onde a herança do tempo de descobertas marítimas e conquistas de territórios foi distribuída de modo heterogéneo entre as pessoas que hoje utilizam a língua portuguesa, ou por extensão a galega, ora como língua materna, como ocorre com muitos de nós, ora como língua segunda ou mesmo terceira. Uma diáspora da riqueza linguística que será frutuosa se, na condição de partícipes em 
condição plurilógica (mais que dialógica), nos propusermos a consolidar uma "comunidade imaginária" transnacional48, respeitando a sua intersecção com outras, a do europeísmo, a da africanidade, a da americanidade, a da asiaticidade, a de cada uma das nacionalidades e localidades, todas em complexo e por vezes sutil processo de mutação e, simultaneamente, em intercâmbios vários.

Como afirma Onésimo Almeida, na conferência "Línguas pátrias de uma lingua expatriada", em que apresenta o posicionamento de vários escritores sobre a lusofonia, "não haverá a saramaguiana jangada de pedra deslocada para o Atlântico Sul", mas "vários desvios" que "aconteceram, acontecem e continuarão a acontecer" 49 .

Neste novo metaparadigma cultural, os investigadores lusófonos têm a oportunidade de interagir de modo original com outras teorizações com o foco, por exemplo, na Pós-colonialidade e/ou na Teoria crítica feminista, pelo que é importante que sejam organizados projetos internacionais que visem à recolha e análise do material específico da lusofonia, uma tarefa em que a Literatura Comparada poderá oferecer um grande contributo para a construção de uma Teoria da Literatura que logre ultrapassar a sua circunscrição eurocêntrica tradicional, revendo criticamente, por exemplo, a sistematização tradicional dos géneros literários, os modos de recepção das obras até então canonizadas, a aplicabilidade dos estilos de época aos atuais polissistemas literários nacionais, com a atenção reforçada sobre a contribuição dos discursos criativos metaficcionais, os quais frequentemente antecipam perspectivas importantes face às informações fornecidas pelos manuais escolares, visto que estes, salvo exceção, servem à sistematização do conhecimento sempre a posteriori ao momento da emergência das novidades. A questão está em reperspectivar a tradição literária canonizada, tendo em vista a dinâmica das realidades da Literatura, de modo a acionar nesta direção o campo de forças da lusofonia enquanto locus de enunciação privilegiado.

Nos termos da tradição teórico-literária eurocêntrica, a contribuição hoje existente no âmbito da lusofonia já é muito rica, mas está marcada pela dispersão, sendo preciso relê-la, recolhê-la, valorizá-la e traduzi-la em 
diferentes idiomas. É preciso ultrapassar a sabedoria autocrática do pseudorrigor científico, marcado por um cosmopolitismo bibliográfico que tende a marginalizar a investigação lusófona ou a absorvê-la com base na estratégia da ocultação das fontes mais próximas a nós, numa guerra de espelhos narcísicos que se ensombrecem sem deixarem ver o nosso contributo comum. E, neste sentido, é muito importante que, por exemplo, a organização do XXII Congresso Internacional de Professores de Literatura Portuguesa (Salvador, Bahia, 2009) tenha programado conferências sobre alguns dos nossos mestres, mestres de mestres, o que favorece as futuras investigações. Por ora, o levantamento desta contribuição teórica escapa ao nosso objetivo de apenas acionar as consciências lusófonas em torno da Literatura Comparada e da Teoria da Literatura em novos moldes, visibilizando-as agora como áreas interdisciplinares de conhecimento no campo dos Estudos Semióticos e Culturais, onde a Literatura continua a ter a sua inalienável existência, carecendo ainda, contudo, de abordagens que organizem o seu conhecimento em novos termos.

Consequentemente, a nossa tarefa consiste em prosseguir para além do ponto em que alguns dos mais conhecidos manuais de Teoria da Literatura estancaram. A titulo de exemplo, e sem desprimor para outros investigadores com quem aprendemos e continuamos a aprender, apenas referirei o manual Teoria da Literatura de Vitor Manuel de Aguiar e Silva, cuja primeira edição é de 1967 e foi muito utilizado pela minha geração de estudantes brasileiros e professores portugueses. Analisando as oito edições que teve esta obra, que já foi considerada uma das cem obras mais lidas em Portugal no século XX, é necessário registrar a enorme diferença entre o texto da sua terceira edição (1979) e o da quarta (1982), a qual se apresenta profundamente reformulada, a prometer um segundo volume jamais vindo: se a terceira edição era constituída por dezasseis capítulos e finalizava com um capítulo restritivo sobre o Estruturalismo, concluído com uma irónica referência ao exorcismo do cientismo pelo prazer do texto segundo Barthes, a quarta edição continha apenas dez capítulos, sendo o referido um dos eliminados, sendo outros revistos e 
outros completamente novos. A orientação teórica continuou totalmente eurocêntrica, uma vez que, salvo alguma rara e eventual referência, é alheia ao contributo ensaístico de autores lusófonos ${ }^{50}$, mesmo os portugueses, fato que não salta logo à vista porque a obra não apresenta uma bibliografia final, apenas notas de fim de página.

$\mathrm{Na}$ edição de 1982, Aguiar e Silva assume radicalmente a expurgação da "função poética", mas o que oferece em troca não chega para um entendimento satisfatório do que seja a Literatura a partir dos seus modos culturais de funcionar. É verdade que a apresenta, como um sistema modelizante secundário, com base na Semiótica da Cultura da Escola de Tartu, uma orientação importante, mas que não deixa de funcionar como uma saída airosa para a indefinição do literário tal como Aguiar e Silva a aborda no seu manual, visto que sistemas modelizantes secundários há muitos ${ }^{51}$. Este acadêmico complementava a sua abordagem com o remetimento para os jogos de linguagem segundo o filósofo Ludwig Wittgenstein, mas isto ainda se mostrava insuficiente para quem tinha a expectativa de conhecer a Literatura com o tipo de «rigor científico" que fora prometido na abertura desta edição.

Fugindo assim da hegemonia do paradigma textualista do estruturalismo, Aguiar e Silva avança para o metaparadigma culturalista, mas estanca diante do abismo que consiste na ameaça ao conhecimento "científico" da Literatura, um conhecimento de teor neopositivista que prometia facultar com base "numa ética do conhecimento e numa ética do exercício da docência universitária»52. Esquecido desta promessa, silencia ante a iminência do abismo camuflado pelo título da sua obra, Teoria da Literatura, deixando os seus leitores, nomeadamente os professores então confiantes na sua palavra, entregues ao nevoeiro de um metadiscurso assertivo, cujo "rigor", prometido na abertura prefacial, é inequivocamente paradoxal, pois os deixava entregues a si mesmos. Um pecado de omissão acadêmica que, no entanto, em nada impediu a massiva existência de outros discursos metaliterários, metaficcionais ou não, diretamente comprometidos com a ostensão das limitações fundamentais da linguagem e com a releitura efetiva da tradição literária. 
A necessidade de enfrentarmos agora o paradoxo do "rigor científico" nos Estudos Humanísticos/ Literários ostenta-se como uma necessidade primeira da nossa autoconsciência profissional nesta era da glocalização, quando se impõe o distanciamento crítico da pretensão epistemológica a um tipo de verdade compreendido ora como positivo ou neopositivo, ora como essencialista. No caso da construção do conhecimento tradicional da Literatura, e da Literatura dita Ocidental, este "rigor", como é sabido, alicerçou-se pela marginalização do "outro", pelo recalque do seu modo de ver e fazer Cultura, de pensar, indagar, teorizar e legitimar o "literário".

Acionando a reflexão teórica de Silvina Rodrigues Lopes, observamos a força do discursivo, do intertextual, do lacunar, do processual e do contratual na construção dinâmica do campo do literário: "Se o literário não existe em si, como tal, é porque é preciso sempre outra palavra que o diga (...): a outra palavra vem sempre suprir a falta que não existe como tal". 53

E, adaptando esta reflexão ao presente contexto, diremos que a construção hegemónica da Teoria da Literatura alienou-se da palavra do "outro", a palavra silenciada onde lemos a inscrição da questão lusófona, uma palavra cuja falta efetivamente parecia não existir como tal ante a ilusão veiculada pelo pretenso rigor "científico" da Teoria da Literatura de teor positivista ou neopositivista. Não se pode perder de vista, de fato, o perspectivismo inscrito em qualquer critério de canonização e de autoridade, mesmo o mais sério e o mais justo. Afinal a consciência da impossibilidade de definir de uma vez para sempre a Literatura decorre da percepção da sua extensão geo-histórica, da sua diversidade situacional, da sua complexidade plurilógica e, assim sendo, a autoconsciência desta impossibilidade deve ser parte integrante da sua compreensão, da sua comunicação e do seu conhecimento processuais, sobretudo no domínio acadêmico dos Estudos Literários.

Derrubados os suportes consensuais da Literatura, uma Literatura sem modificador que a especifique, ficou-nos, como docentes, o desafio de tentar contribuir para conhecê-la melhor, mas de modo consciente e explicitamente glocalocalizado. 
O desafio de agora à lusofonia é este: recolher, ler e reler, analisar, comparar e avaliar as contribuições dos Estudos Literários e congêneres, de modo a que possam ser construídas propostas originais, inclusive examinando, no domínio canonizado da Teoria da Literatura, até que ponto categorias teóricas e geo-históricas como, por exemplo, os gêneros do discurso literário e os estilos de época nas Literaturas Europeias, na medida em que tendem a transformar-se em etiquetas escolares que mecanizam o conhecimento, nos impedem de ver, e ver criticamente sem preconceitos, as novidades específicas das realidades polissistêmicas das Literaturas Coloniais e Pós-coloniais no seu esforço para dizer as diferenças.

A periferia teórica tem sido o lugar mais constante da lusofonia ${ }^{54}$. No panorama internacional que a excede, só muito raras vezes um estudo escrito em português ou em galego é referido. Não importa que, nos países e comunidades lusófonas esparsas pelo mundo, haja excelentes trabalhos no campo da Teoria da Literatura e da Literatura Comparada, como sabemos que, de fato, existem. O que se passa? Provavelmente o desequilíbrio da nossa balança de importação e exportação de traduções tenha responsabilidade, mas isto não explica tudo. Não temos economias que nos permitam ser pássaros, o que também não explica tudo, pois há exceções. Porém, com as devidas diferenças, e há muitas, o que mais temos em comum é um passado de subordinação a interesses econômicos estranhos - um problema de colonização e neocolonização a que não escapou nem mesmo Portugal, cujo endividamento externo acabou por comprometer a sua razão imperial.

Sejamos realistas que o espelho tem que estar iluminado para que nos organizemos melhor, sem pruridos imperiais, coloniais, neocoloniais, étnicos, religiosos e outros. De momento, façamos desta imagem inicial nada mais que um bom motivo para saltar, já que não podemos voar, agarrando a oportunidade que nos faculta o presente metaparadigma cultural para sairmos do silêncio em que nos temos encontrado desde há séculos. 


\section{NOTAS}

${ }^{1}$ A supremacia do paradigma textualista sobre o historicista impôs-se na Europa Ocidental a partir dos estudos de Estilística e, nomeadamente, da antologia de textos do Formalismo russo, Théorie de la Littérature, organizada e traduzida pelo investigador búlgaro Tzvetan Todorov, em 1965.

${ }^{2} \mathrm{O}$ conceito de Literatura como arte da palavra - fora do seu exagerado alargamento no âmbito do paradigma historicista proveniente do século XIX, onde se confundia com erudição - estreitou-se com o paradigma textualista, que privilegiava as obras poético-ficcionais como produtos acabados, contudo, o paradigma culturalista complexifica a delimitação da Literatura ao conceber estas obras como produções dinâmicas do autor e dos receptores, o que leva à revisão das funções dos metadiscursos na construção do espaço cultural, onde estes se integram como elementos comunicacionais interativos e constitutivos. (Registre-se que o ordenamento dos paradigmas literários apresenta variantes: E. Prado Coelho reconhecera o filológico, maioritário, preso à delimitação de um sentido textual único e à intenção do autor nas duas vertentes, a historicista e a formalista; o comunicacional, comprometido com a noção de verdade intersubjetiva nas três vertentes, a erótica, a tecnocrática, a histórica ligada à estética da recepção; o metapsicológico, baseado na falta de coincidência entre verdade e sentido nas vertentes psicanalitica e na metafísica-Id., 1982: 15-16).

3 Segundo Van Tieghem (1921, p. 254-260), os estudos de Literatura Comparada deveriam incidir sobre duas ou três literaturas, enquanto que os de Literatura Geral deveriam focar fenómenos que transcendessem as fronteiras nacionais, como os movimentos literários. A identidade da Literatura Geral envolve ainda, uso da expressão "literatura mundial" e da palavra "Weltiteratur» (cf. Prawer, 1973, in Bassnett et alii, 1998:21-35).

${ }^{4} \mathrm{Na}$ vocação internacional da Teoria da Literatura/ Literatura Comparada está implicada a realidade dos "trânsitos" geográficos, viagens, diásporas e exílios, por exemplo: René Wellek (1903-1995), deslocado para os Estados Unidos durante a II Guerra Mundial, nasceu em Viena e viveu também em Praga, sendo de família de origem tcheca; Erich Auerbach, de naturalidade alemã, exilou-se na Turquia e nos Estados Unidos; Edward W. Said nasceu em Jerusalém, na Palestina (anteriormente à formação de Israel), viveu no Egito e também nos Estados Unidos.

5 Wellek, 1946, in 1963: 223-243.

6 Id., 1946, in 1963, p. 224).

7Proferida no II Congresso da Associação Internacional de Literatura Comparada (A.I.L.C./ I.A.C.L.), em Chapel Hill.

8 Wellek, 1958, in 1963: 244-255.

${ }^{9}$ In Machsey - Donato, orgs, 1970:247-264; cf. Derrida, 1967. O filósofo francês de origem argelina proferiu esta conferência no Congresso The Languages of Criticism and the Sciences of Man, realizado pelo Humanities Center/ The Johns Hopkins University.

${ }^{10}$ Barthes, 1966:14-16 (Esta obra integra-se na polémica com Picard, 1965).

${ }^{11}$ Id., op.cit.: $16-40$.

12Trata-se de documentos elaborados por comissões identificadas pelos nomes dos respectivos secretários, respectivamente Harry Levin, Thomas Greene e Charles Bernheimer.

13 Embora identificado pelo sobrenome do secretário da comissão, "O Relatório Bernheimer, 1993. Literatura Comparada na transição do século" foi submetido à associação por dez membros. Além de Charles Bernheim: Jonathan Arac, Marianne Hirsch, Ann Rosalind Jones, Ronald Judy, Arnold Krupat, Dominique La Capra, Sylvia Molloy, Steve Nichols, Sara Suleri. O texto encontra-se disponível, em inglês, na internet, mas pode ser encontrado em português, na trad. de M. Helena Serôdio, na abertura da excelente coletânea organizada por Helena Buescu, João Ferreira Duarte e Manuel Gusmão, 2001: 17-36, que utilizamos.

14 Bernheimer et alii, 1993, p. 18. 
15 Id, op.cit.: 20, itálicos nossos. O verdadeiro busílis está no problema da identificação da Literatura, que é acima de tudo manifestação estética, embora não circunscrita à alta de elite. O prazer do texto, ler-escrever-interpretar, tem os seus graus e os seus modos de concretização. Variavelmente modulada, a Literatura justifica-se ora pelo próprio discurso que lemos com estremecimento interior, mas cuja tessitura cabe ao autor; ora deriva das diferentes formas de ler e valorizar, o que é mais da índole ou da responsabilidade deste ou daquele receptor e das comunidades históricas a que estes pertencem; ora a literatura é também produzida pela convergência de forças institucionais, desde a tradição literária e a escola ao comércio editorial e à política; ora implica tudo isto. A identificação do que seja Literatura não se sujeita a consensos absolutos, nem a evidências do gênero de 2 e 2 são 4 , embora o conhecimento crítico e teórico possa tratar este objeto de estudo em termos de probabilidade cultural localizável histórica, geográfica e socialmente.

16 Eagleton, 1983: 1-17.

${ }^{17} I d$., op.cit., p.232.Recorde-se o dito anteriormente, na p. 213 - "A 'literatura', conforme observou Roland Barthes, 'é aquilo que é ensinado'". Este contexto permitenos inferir que a Literatura padecera de doença metafisica e formalista.

${ }^{18}$ Estas correntes distribuem-se pelos seguintes capítulos (Id., op.cit.: 59-232): "Fenomenologia, Hermenêutica e Teoria da Recepção", "Estruturalismo e Semiótica", "Pós-estruturalismo" [inclui a Desconstrução], "Psicanálise", "Conclusão: Crítica política"

19 «By "theory" we mean a special project in literary criticism: the attempt to govern interpretations of particular texts by apealing to an account of interpretation in generaln; "Our thesis has been that no one can reach outside practice, that theory should stop trying, and that the theorical enterprise should therefore come to the end" (Knap Michaels, in W.J.T. Mitchell, org., 1985: 11 e 30. Na mesma obra, afirma-se que a "theory is not consequential even when the practitioner is himself a theorist" (Fish, "Consequences", p.124).

20 Asiáticos, Africanos, Latino-Americanos, etc. Ver Spivak, 2003.

${ }^{21}$ Miner, 1990.

22 Rorty, 1982

23 Jacques Derrida, Michel Foucault, Luce Irigaray, Jacques Lacan, Louis Althusser, Gayatri Spivak, etc.

${ }^{24}$ Foucault, 1976.

25 „'Il n'y a pas de hors-texte' (Derrida, 1967b) - 'There is no outside-of-texte': when you are getting outside signs and text, to 'reality itself', what you find is more text, more signs, chains of suplements", Culler, op.cit., p.12.

${ }^{26}$ Uma questão sobre a qual incidiu a nossa tese de doutoramento, 1995, e que desenvolvemos em trabalhos posteriores.

27 Culler, 1997: 4 -5, itálicos nossos.

28 Cf. Kuhn, 1962, 1969, 1974.

${ }^{29}$ Culler, 1997, p. 5. Cf. .Barthes, 1968; Foucault, 1969; Buescu, 1998.

30 Mignolo, 1991: 234-235.

31 É esta a postura de Aguiar e Silva no conhecido manual, Teoria da Literatura (1967), que, a partir da sua quarta edição (1981), surge profundamente reescrito e com uma tonalidade prefacial bem demarcada pela retórica da racionalidade: "Um livro científico-didático que não se renove, com o espírito de rigor que deve caracterizar a docência e a investigação universitárias, é um livro condenado a morte breve. [...] $\mathrm{Na}$ última década, a Teoria da Literatura, em particular no seu interface com outras disciplinas, conheceu profundas modificações. [...] A racionalidade científica, todavia, se é incoadunável com o fixismo teorético, é incompativel também com qualquer espécie de cepticismo ou relativismo gnoseológicos que impliquem a corrosão dos próprios fundamentos dessa racionalidade e gerem a confusão anarquizante de conceitos, métodos, etc."

32 de Man, 1971.

${ }^{33}$ No caso de Aguiar e Silva, por exemplo, que fora deputado no regime político anterior à revolução de Abril de 1974 em Portugal, "O espírito de rigor" não o impediu de 
omitir (1981ss) a teorização marxista sobre a Literatura, cuja importância no século XX não poderia deixar de ser abordada com distanciamento ideológico por quem dizia pôr o conhecimento objetivo acima das razões pessoais.

34 Pozuelo Yvancos - Aradra Sánchez, 2000: 17.

35 Even-Zohar, 1979, 1990, 2004.

36 Beauvoir, I, (1949), 1976, p.20.

37 A Nova História/ Teoria da ego-história (Nora, 1987) tem despertado interesse pela análise da relação entre a biografia do sujeito e a sua obra científica, inclusive dando lugar a uma "historiografia autobiográfica" (Jauss, 1989). Estas propostas foram comentadas por Heidrun K. Olinto, no ensaio "Historiografia (literária) à flor da pele" (2005, p.140-154), onde também comenta o caso de Paul de Man, a estratégia de ocultamento do seu passado nazista, a troca de identidade, a desconstrução e o seu projeto de fundação de novos Estudos Literários.

38 Esta corrente ganha visibilidade a partir de 1978, ano da publicação de Orientalism, de Edward Said. Este marco, porém, não nega a importância de representantes anteriores, a exemplo do psiquiatra e psicanalista antilhano Franz Fanon, cujo livro, Les damnés de la terre, 1961, foi apoiado pelo intenso prefácio de Jean-Paul Sartre, ao tempo da guerra da Argélia (1952-1962).

39 Benveniste, 1966; Lacan, 1966; Barthes, 1968; Buescu, 1998.

40 Sousa Santos, 1987.

${ }^{41}$ Kuhn, 1962 e 1969.

44.

${ }^{42}$ Featherstone - Lash - Robertson, orgs., 1995, especialmente Robertson, pp.25-

43 Itamar Even-Zohar, "Polysistem Theory", Poetics Today, 1, 1-2, 1979: 287-310; "Polysistem Studies", ed rev. Poetics Today, 11, 1, 1990: 6-26; "Polysistem Theory (revised)", in Papers in Culture Research, 2004, in

http://www.tau.ac.il/ itamarez/works/books/ez-cr2004.pdf

44 Mignolo, 1991, p. 235.

45 Cito dois exemplos, o do autor de um conhecido e muito peculiar manual de Teoria da Literatura e o da autora de uma vasta reflexão sobre diferentes ramos do conhecimento teórico na actualidade: a) "En épocas de pensamiento fragmentario y debilitado parece atrevido e insólito proponer una teoría global de una rama del saber.[...] Me parece que, hoy como siempre, permanecen intactas las razones que hacen de los objetos estéticos, de las obras de arte, mensajes, testimonios y desafios útiles para el conocimiento del hombre [...]" (García Berrio, 1988: 9);

b) "Não é que se justifique a preocupação de uniformização de linguagens, de modo a eleger-se uma perspectiva hegemónica dos estudos literários ou uma orientação teorética que ignore completamente as outras teorias, mas há que dar uma perspectiva ao mesmo tempo plural e coerente, de modo a que os alunos construam o seu próprio saber conscientes dessa pluralidade e dos caminhos que se lhes oferecem" (Goulart, 2000: 1).

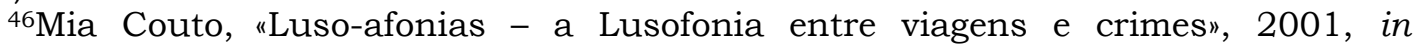
2009:183-198.

47 Lyotard, 1979.

48Aplica-se à formação de comunidades transnacionais, como a lusofonia, a noção de "comunidade imaginária", usualmente referida ao nacionalismo (cf. Anderson, 1991).

49 Almeida, 2005, p.37.

50 A substancial e original tese de Costa Lima, Estruturalismo e Teoria da Literatura, por exemplo, já havia sido publicada comercialmente desde 1973.

${ }^{51}$ Lotman (1970), dentre outros.

52 "Prefácio" (1981), in Teoria da Literatura, $8^{\text {a }}$ ed., 1990.

53 Lopes, 1994: 476.

54 O complexo polissistema multicultural da lusofonia é constituído por Portugal, pela região de Macau e pelos países por ele colonizados - Angola, Brasil, Cabo Verde, Guiné-Bissau, Moçambique, S. Tomé e Príncipe, Timor Leste; pela Galiza e por pessoas e 
comunidades esparsas pelo mundo que se servem do português e do galego como língua nativa ou como língua de afeto por descendência ou especialização.

\section{Referências Bibliográficas:}

ALMEIDA, Onésimo T. "Línguas-pátria de uma língua expatriada", in M P. Campos Fernandes, org., 2005: 29-38.

ANDERSON, Benedict, Imagined Communities: Reflection on the Origin and Spread of Nationalism, revised edition, London- New York: Verso, 1991.

BARTHES, Critique et verité. Paris: Seuil, 1966, trad. M. Cruz Ferreira, Critica e verdade. Lisboa: Edições 70, 1978.

. "La mort de l'auteur" (1968), rep. in Le bruissement de la langue.

Paris: Seuil, 1984: 61-67.

BASNETT, Susan et alii. Orientaciones en Literatura Comparada, org. Dolores Romero López. Madrid: Arco: Libros, 1998.

BEAUVOIR, Simone (1949), Le deuxième sexe, I-II, Paris: Gallimard, ed. ren. 1976.

BERNHEIMER, Charles et alii. "Bernheimer Report, 1993. Comparative Literature at the Turn of Century", in Charles, Bernheimer, org. 1995, p.39-48; cf. trad. M. Helena Serôdio, "O Relatório Bernheimer, 1993. Literatura comparada na transição do século", in Helena Buescu - João F. Duarte - Manuel Gusmão, orgs. 2001, op.cit.:17-36. Disponivel em inglês:

http:/ / www.umass.edu/complit/aclanet/SyllPDF / Bernheim.pdf

BERNHEIMER, Charles, org. Comparative Literature in the Age of Multiculturalism. Baltimore: Johns Hopkins University Press, 1995.

BUESCU, Helena. Em busca do autor perdido - histórias, concepções, teorias. Lisboa: Cosmos, 1998.

. "Literatura Comparada e Teoria da Literatura: relações e fronteiras", in Helena Buescu - João Ferreira Duarte - Manuel Gusmão, orgs. 2001: 83-100.

BUESCU, Helena - DUARTE, João Ferreira - GUSMÃO, Manuel, orgs. Floresta encantada. Novos caminhos da Literatura Comparada. Lisboa: D. Quixote, 2001.

CAMPOS FERNANDES, M. da Penha. Mimese irónica e metaficção - para uma poética pragmática do romance (contemporâneo). Braga: Universidade do Minho, 1995.

. UUma outra história: estética da recepção, ruptura, filtro iluminista e mimese poética", in M. da Penha Campos Fernandes, org. 2005: 259280.

.Poética e metapoéticas: 'cânone europeu' e Literatura Colonial no Brasil", in Limite, 2, História na(s) Literatura(s)em lingua portugiuesa, 20089:187-230. Disponível em: 
http:/ / www.revistalimite.es/volumen2.htm1

CAMPOS FERNANDES, M. da Penha, org. História(s) da Literatura, Actas do I. Congresso Internacional de Teoria da Literatura e Literaturas Lusófonas, Braga - Coimbra: Universidade do Minho - Almedina, 2005.

CARVALHAL, Tânia Franco. "O reforço teórico", in Literatura Comparada. 2. ed. rev. ampl., S. Paulo: Ática, 1992: 45-74.

COHEN, R., org. Future Literary Theory. New York- London: Routledge, 1989.

COSTA LIMA, Luís. Estruturalismo e Teoria da Literatura. Introdução às problemáticas estética e sistémica. Petrópolis: Vozes, 1973.

COUTO, Mia Couto. "Luso-afonias - a Lusofonia entre viagens e crimes" (2001), in E se Obama fosse africano? Lisboa: Caminho, 2009:183-198.

CULLER, Jonathan. "Comparative Literature and Literary Theory" (1979), trad. Dolores Romero López, in Susan Bassnett et alii, pp.106-124.

.Literary Theory. A Very Short Introduction. Oxford: Oxford University Press, 1997.

DERRIDA, Jacques. "Structure, Sign and Play in the Discourse of Human Science" (1966) in R. Macksey R.- E. Donato, orgs, 1970: 247-264. .L'écriture et la différence, Paris: Seuil, 1967a.

De la grammatologie. Paris: Minuit, 1967b.

EAGLETON, Terry. Literary Theory, an Introduction. Oxford: Basil Blackwell, 1983, trad.Waltensir Dutra, s.d.

Teoria da Literatura: uma introdução. São Paulo: Martins Fontes,

After Theory. Londres: Penguin Books, 2004.

FEATHERSTONE, Mike - LASH, Scott- ROBERTSON, Roland, orgs. Global Modernities. London: Sage Publications, 1995.

FISCH, Stanley. "Consequences", in Mitchell, W.J.T, org. 1985, p.124.

FOUCAULT, Michel. "Qu'est-ce que un auteur ?", in Bulletin de la Societé Française de Philosophie, 63e. année, $\mathrm{n}^{\circ} .3$, juillet-septembre, 1969: 96104.

FOUCAULT, Michel. Histoire de la sexualité, I, La volonté de savoir. Paris: Gallimard, 1976.

GARCÍA BERRIO, Antonio. Teoría de la Literatura. Madrid: Cátedra, 1988.

GOULART, R. M. Literatura e Teoria da Literatura em tempo de crise. Braga: Angelus Novus, 2000.

JAUSS, Hans R. "Historia calamitatum et fortunarum mearum or: Paradigm Shift in Literary Study, in R. Cohen, org., 1989.

KNAP, S. - MICHAELS, W. Ben. "Against Theory", in Mitchell, W.J.T, org. 1985: 11 e 30 .

KHUN, Thomas S. The Structure of Scientific Revolution (1962). 2a . ed., trad. Beatriz V. Boeira - Nélson Boeira, A estrutura das revoluções científicas. 3. ed. S. Paulo: Perspectiva, 1991, contém o "Pósfacio 1969" ["Postcript -1969»]: 217-256.

LABAN, Michel., Encontro com escritores, I-VIII, Porto: Fundação Engenheiro António de Almeida, 1992-2002.

LOPES, Silvina Rodrigues, A legitimação em Literatura, Lisboa: Cosmos, 1994. 
LOTMAN, Iouri. Struktura chudozestvennogo teksta (1970), trad. H. Meschonnic, La Structure du Texte Artistique, Paris: Gallimard, 1973. LYOTARD, Jean-François. La condition postmoderne. Paris: Minuit, 1979. MACHADO, Álvaro Manuel - PAGEAUX, Daniel-Henri. "Para uma Teoria da Literatura", in Álvaro M. Machado - Daniel-Henri Pageux, Literatura Portuguesa, Literatura Comparada e Teoria da Literatura. Lisboa. Edições 70, 1981: 99-128.

MACKSEY, Richard - DONATO, Eugenio, orgs. The Structuralist Controversy. The Languages of Criticism and the Sciences of Man. Baltimore: The John Hopkins University Press, 1970.

MAN, Paul de. Blindness and Insight, Essays in the Rhetoric of Contemporary Criticism (1971), 2.ed. rev. Minnesota: University of Minnesota Press, 1983.

MINER, Earl. Comparative Poetics: an Intercultural Essays on Theories of Literature. Princeton, New Jersey: Princeton University Press, 1990.

MIGNOLO, Walter. "Canon and corpus. An Alternative View of Comparative Literary Studies in Colonial Situations, in Dedalus Revista Portuguesa de Literatura Comparada, I, 1991: 219-244.

MITCHELL, W.J.T., org. Against Theory: Literary Studies and New Pragmatism. Chicago: Chicago University Press, 1985.

NORA, Pierre. Essays d'ego-histoires. Paris: Gallimard, 1987.

OLINTO, Heidrun Krieger. "Historiografia (literária) à flor da pele", in CAMPOS FERNANDES, M.P., org., 2005, p.140-154.

PICARD, Raymond. Nouvelle critique ou nouvelle imposture.Paris : J.J.Pauvert, 1965.

POZUELO YVANCOS, José María - ARADRA SÁNCHEZ, Rosa María. Teoria del canon y Literatura española. Madrid: Cátedra, 2000.

PRADO COELHO, Eduardo. Os Universos da Critica. Lisboa: Edições 70, 1982.

PRAWER, S.S. "What is Comparative Literature?" (1973), trad. Félix Rodríguez, "¿Qué es la Literatura Comparada?", in Susan Bassnett et alii, 1998: 21-35.

ROBERTSON, Roland. "Glocalization: time-spice and homogenityheterogenity", in Featherstone - Lash - Robertson, orgs.1995: 25-44.

RORTY, Richard. Consequences of Pragmatism, Minneapolis: University of Minnesota Press, 1982.

SILVA, Vítor M. de Aguiar. Teoria da Literatura (1967), 3., 4. e 8. ed.,Coimbra: Almedina, 1979, 1981, 1990.

SOUSA SANTOS, Boaventura. Um discurso sobre as ciências (1987). 12. ed. Porto: Afrontamento, 2001.

SPIVAK, Gayatri Chakravorty. Death of a Discipline.N. York: Columbia University Press, 2003.

TIEGHEM, Paul Van, "La synthèse en histoire littérature: littérature comparée et littérature générale", in Revue de synthèse historique, XXXI, 1921: 254-260.

TODOROV, Tzvetan. Théorie de la littérature, textes des formalistes russes. Paris: Seuil, 1965. 
WELLEK, René - WARREN, Warren. Theory of Literature (1949). 3. ed. rev., 1962, trad. Luis Carlos Borges, rev. Silvana Vieira - Valter Siqueira. Teoria da Literatura e metodologia dos estudos literários. S. Paulo: Martins Fontes, 2003.

WELLEK, René. Concepts of Criticism. (1963), trad. Óscar Mendes. Conceitos de Critica, S. Paulo: Cultrix, s.d. .Discriminations: Further Concepts of Criticism. New Haven: Yale University Press, 1970. 